\title{
Erratum
}

\section{CSF cholecystokinin, $\gamma$-aminobutyric acid and neuropeptide $Y$ in pathological gamblers and healthy controls}

\author{
C. Nordin, I. Sjödin \\ [J Neural Transm 114 (2007) 499-503: DOI 10.1007/s00702-006-0593-4]
}

In the above-mentioned paper we erroneously reported the denomination of $\gamma$-aminobutyric acid (GABA) in CSF to be pmol/l (Table 2). The correct denomination is $\mu \mathrm{mol} / 1$. The authors regret this error and any inconvenience it may have caused.

Correspondence: Professor Conny Nordin, Department of Neuroscience and Locomotion, Psychiatry Section, Faculty of Health Sciences, Linköping University, SE-581 85 Linköping, Sweden; e-mail: conny.nordin@inr.liu.se 